\title{
Effect of Carbamazepine and Sodium Valproate on Liver Enzymes of Epileptic Children
}

\author{
Abdelmoneim Mahgoub ${ }^{1}$, M. Abdoun ${ }^{1 *}$, (D), Sohail Azam ${ }^{2,}$ (D), Reham Babiker ${ }^{1}$ \\ ${ }^{1}$ Department of Pediatric, Arryan Hospital, Dr Sulaiman Al Habib Medical Group, Khurais Road, P.O. Box 100266, Riyadh 11635, Saudi Arabia \\ ${ }^{2}$ Department of Inpatient Pharmacy, Arryan Hospital, Dr Sulaiman Al Habib Medical Group, Riyadh, Saudi Arabia
}

\author{
ARTICLE INFO \\ Article History \\ Received 06 June 2020 \\ Accepted 22 August 2020 \\ Keywords \\ Antiepileptic medications \\ epilepsy \\ aspartate aminotransferase \\ alanine aminotransferase \\ carbamazepine \\ sodium valproate \\ pediatric
}

\begin{abstract}
Carbamazepine and sodium valproate are one of the most common antiepileptic medications used in clinical practice. The period of treatment is commonly associated with benign alternation of the liver enzymes due to drug metabolism. Evaluation of asymptomatic enzymatic changes could be challenging to the expert clinician and may expose patients to unnecessary procedures or expenses. Thus, this article aims to focus on the frequency of liver enzyme abnormalities among epileptic children. For this, an analytic cross-sectional study was conducted in 100 epileptic patients who received carbamazepine or sodium valproate for 1 year. Those with healthy pretreatment liver enzymes were recruited for the study. The results showed an elevation of Aspartate Aminotransferase (AST) in $24 \%$ of the patients treated with sodium valproate $(p=0.01)$ and $20 \%$ of the patients treated with carbamazepine. Alanine Aminotransferase (ALT) was elevated in both groups to a similar extent, $6 \%(p=0.01)$. In conclusion, the study showed a lower proportion of liver enzyme abnormalities, since AST is a less sensitive biomarker when compared to ALT. No measurement exceeds twice the average value, nor are there any clinical abnormalities. There is no proven value of routine liver enzyme measurement in asymptomatic patients in our study. However, baseline enzyme tests are recommended. Further controlled studies on a larger sample size are required.
\end{abstract}

(C) 2020 Dr. Sulaiman Al Habib Medical Group. Publishing services by Atlantis Press International B.V. This is an open access article distributed under the CC BY-NC 4.0 license (http://creativecommons.org/licenses/by-nc/4.0/).

\section{INTRODUCTION}

The word epilepsy is derived from the Greek word epilam-banein, which means to seize [1]. Epilepsy is defined as a group of abnormal neurological disorders characterized by recurrent unpredictable activities [2]. The underlying mechanism of epilepsy is not fully understood; however, a disturbance within excitatory and inhibitory signals in the brain tissue has been defined [3]. The prevalence of epilepsy is estimated at 4-10/1000 worldwide, and 60\% of these cases start in childhood [4]. Patients are diagnosed with epilepsy if they have two unprovoked seizures that were unable to be explained by a reversible medical condition [5]. These seizures are usually recurrent and self-limited; however, physical injury, including bone fracture or bleeding, can complicate status epileptics [6].

The goal of treatment is to achieve seizure control with minimum side effects. Carbamazepine and sodium valproate are widely used antiepileptic in pediatric practice. Carbamazepine acts mainly by blocking the sodium channel and reducing cell excitation [7]. Sodium valproate acts by potentiating the inhibitory neurotransmitter, gamma-aminobutyric acid [8].

Prolonged treatment may expose children to various forms of hepatocellular injuries. Up to $25 \%$ of treatment failure has been

"Corresponding author. Email: abdoonson111@gmail.com

Peer review under responsibility of the Dr. Sulaiman Al Habib Medical Group Data availability statement: The data that support the findings of this study are available from the corresponding author [M.A.], upon reasonable request. attributed to adverse antiepileptic drugs [9]. They can be an acute allergic reaction or dose-dependent. The unpredictable reaction is often idiosyncratic and requires a change of medication. Dosedependent drug reactions usually worsen with increasing treatment [9]. Side effects include cognitive functions, emotional well-being, as well as the motor and somatic functions [10].

Hepatic aminotransferase, including Alanine Aminotransferase (ALT) and Aspartate Aminotransferase (AST), are useful biomarkers for liver injuries [11]. However, a benign elevation of liver enzymes is commonly reported in asymptomatic patients due to drug metabolism [12]. Further investigations are warranted if the tests double or triple the standard upper limit [13]. Indiscriminate liver enzyme testing during anticonvulsant treatment is not recommended $[14,15]$. Routine screening can end with improper clinical decisions or stopping medications. Thus, our study aims to evaluate the effect of carbamazepine and sodium valproate on the liver enzymes of epileptic children. This, besides further research, will help us to improve pediatric practice.

\section{PATIENTS AND METHODS}

The study was conducted in the pediatric department and neurology clinic at Arryan Hospital/Dr Sulaiman Al Habib Medical Group (HMG; Riyadh, Saudi Arabia). HMG is a private tertiary center, Joint Commission International-accredited hospital. The study was approved by the HMG Institutional Review Board (Approval No: RC18.11.24). 
It is an analytic cross-sectional study that aims to review the serum liver enzymes of all patients treated for epilepsy with either carbamazepine or sodium valproate at the aforementioned hospital. The inclusion criteria were epileptic patients of either sex between the ages of 1 and 15 years, patients with healthy pretreatment liver enzymes, and patients on antiepileptic medications for at least 12 months and within the therapeutic drug level. Our exclusion criteria were patients with any known liver disease, those who have used other drugs directly affecting the liver, and those on multiple antiepileptic or noncomplaints. The study population were divided into two groups: Group I for carbamazepine patients $(15-20 \mathrm{mg} / \mathrm{kg} / \mathrm{day}$, divided twice daily) and Group II for sodium valproate (25-30 mg/ $\mathrm{kg} /$ day divided twice daily) [16]. Patients with normal pretreatment liver enzyme levels were recruited for this study. We checked the serum liver enzymes (AST, ALT) of the patients 12 months after the treatment. Meanwhile, the patients were subjected to careful clinical evaluation (history and examination) for signs and symptoms of hepatic dysfunction, which includes vomiting, nausea, jaundice, oedema, right hypochondrial pain, or hepatomegaly. Enzymes were taken from peripheral venous blood samples and were analyzed by an Architect 1000/Abbott machine (https://www.corelaboratory.abbott/int/en/ offerings/brands/architect). The reference values of enzymes were: AST 10-40 IU/L and ALT 9-40 IU/L.

The data were collected from an electronic hospital record system (volunteers for intercultural and definitive adventures) and categorized on Microsoft Office Excel 2010 (Microsoft Corporation, Redmond, WA, USA). Our parameters included age, sex, and serum liver enzymes (AST and ALT) prior to and 12 months after the treatment for each group, in addition to the parameter of clinical evaluation.

Statistical analysis was performed using SPSS version 19 (SPSS Inc., Chicago, IL, USA). Data were presented as descriptive statistics [mean \pm Standard Deviation (SD) for continuous data and proportion for categorical data]. A matched paired $t$-test was used to compare liver enzymes prior to and after the treatment. Student $t$-test and Chi-square test were used to measure continuous and categorical data, respectively. Logistic regression analysis was incorporated to estimate the impact of demographic variables on the liver enzymes abnormalities. Statistical significance was measured with $p<0.05$.

\section{RESULTS}

\subsection{Description of the Study Population}

We initially identified electronic records of 115 patients treated for epilepsy with either carbamazepine or sodium valproate at Dr Sulaiman Al Habib Medical Group. Among these, 15 patients were excluded (nine of the carbamazepine group and six of the sodium valproate group), as shown in Figure 1. A total of 100 patients met the necessary inclusion criteria and were considered for the study.

The study population were divided according to the medications used: Group I consisted of patients who were treated with carbamazepine (50 cases) and Group II comprised those who were given sodium valproate (50 cases). The age group ranged from 1 to 15 years, with a mean of $7.43 \pm 3.83$. The sex distribution was $56 / 100$ for males (56\%) and 44/100 for females (44\%). Demographic differences among the study groups prior to the treatment are shown in Table 1.

\subsection{Liver Enzymes Values among Participants}

The difference in pretreatment liver enzymes among the study groups is illustrated in Table 2. The values are not statistically significant.

The mean levels of AST and ALT prior to and 12 months after the treatment are presented in Tables 3 and 4, respectively.

\section{Exclusion}

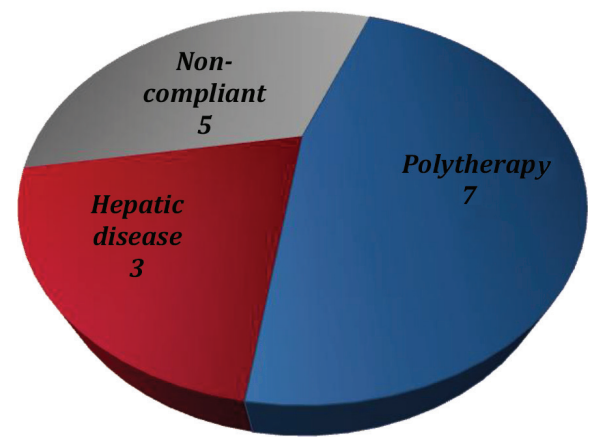

Figure 1 Number of excluded cases based on study criteria.

Table $1 \mid$ Baseline characteristics of the study population ${ }^{\mathrm{a}}$

\begin{tabular}{lccc}
\hline Variable & $\begin{array}{c}\text { Carbamazepine } \\
(\boldsymbol{n}=\mathbf{5 0})\end{array}$ & $\begin{array}{c}\text { Sodium valproate } \\
(\boldsymbol{n}=\mathbf{5 0})\end{array}$ & $\boldsymbol{p}$ \\
\hline Age & $6.92 \pm 3.16$ & $7.94 \pm 4.37$ & 0.1 \\
Sex & Male: 26, Female: 24 & Male: 29, Female: 21 & 0.3 \\
\hline
\end{tabular}

andependent-samples $t$-test was used to calculate $p$-values $(p<0.05)$.

Table 2 Baseline liver enzymes difference among the study population ${ }^{\mathrm{a}}$

\begin{tabular}{lccc}
\hline Variable & Carbamazepine & Sodium valproate & $p$ \\
\hline $\begin{array}{l}\text { AST }(10-40 \mathrm{IU} / \mathrm{L}) \\
\text { Mean } \pm \text { SD }\end{array}$ & $21.44 \pm 4.38$ & $22.96 \pm 4.72$ & 0.9 \\
$\begin{array}{l}\text { ALT }(8-40 \mathrm{IU} / \mathrm{L}) \\
\text { Mean } \pm \text { SD }\end{array}$ & $13.78 \pm 5.06$ & $13.06 \pm 3.96$ & 0.4 \\
\hline
\end{tabular}

andependent-samples $t$-test was used to calculate $p$-values $(p<0.05)$.

Table 3 Mean level of aspartate aminotransferase before and after medication $^{\mathrm{a}}$

\begin{tabular}{lccc}
\hline Medications & Before & After 1 y & $\boldsymbol{p}$ \\
\hline Carbamazepine & $21.44 \pm 4.38$ & $27.90 \pm 12.01$ & 0.01 \\
Sodium valproate & $22.96 \pm 4.72$ & $29.26 \pm 11.76$ & 0.01 \\
\hline
\end{tabular}

apaired-samples $t$-test was used to calculate $p$-values $(p<0.05)$.

Table 4 Mean level of alanine aminotransferase before and after medication ${ }^{\mathrm{a}}$

\begin{tabular}{lccc}
\hline Medications & Before & After $\mathbf{~ y ~}$ & $\boldsymbol{p}$ \\
\hline Carbamazepine & $13.78 \pm 5.06$ & $16.40 \pm 8.60$ & 0.02 \\
Sodium valproate & $13.06 \pm 3.96$ & $16.42 \pm 10.41$ & 0.04 \\
\hline
\end{tabular}

aPaired-samples $t$-test was used to calculate $p$-values $(p<0.05)$. 
Comparison of the mean of liver enzymes between the groups after 12 months of antiepileptic treatment is illustrated in Table 5.

AST and ALT values 12 months after the treatment were distributed according to the frequency of cases in Figures 2 and 3, respectively.

\subsection{Correlation between Liver Enzymes and Baseline Variables}

Demographic differences between the study groups after treatment are shown in Tables 6 and 7, respectively.

Table 5 Effect of carbamazepine and sodium valproate after 12 months ${ }^{\mathrm{a}}$

\begin{tabular}{lccc}
\hline Variable & Carbamazepine & Sodium valproate & $p$ \\
\hline $\begin{array}{l}\text { AST }(10-40 \mathrm{IU} / \mathrm{L}) \\
\quad \text { Mean } \pm \text { SD }\end{array}$ & $27.90 \pm 12.01$ & $29.26 \pm 11.76$ & 0.5 \\
$\begin{array}{l}\text { ALT }(8-40 \mathrm{IU} / \mathrm{L}) \\
\text { Mean } \pm \text { SD }\end{array}$ & $16.42 \pm 8.60$ & $16.42 \pm 10.41$ & 0.9 \\
\hline
\end{tabular}

andependent $t$-test was used to calculate $p$-values $(p<0.05)$.

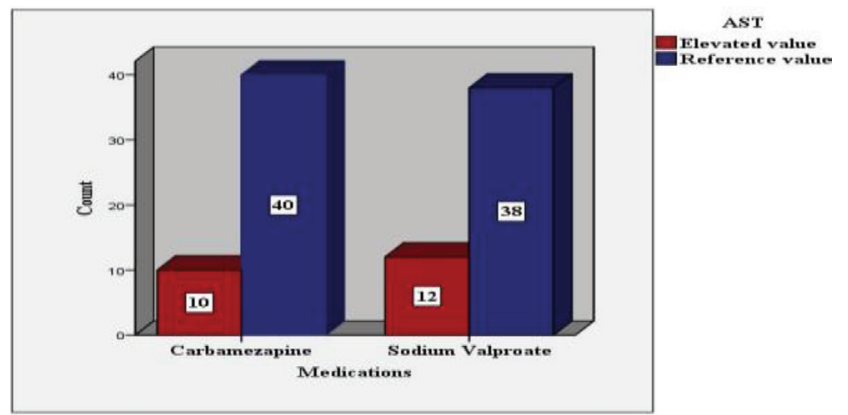

Figure 2 AST level after 12 months of antiepileptic treatment according to the frequency of the cases.

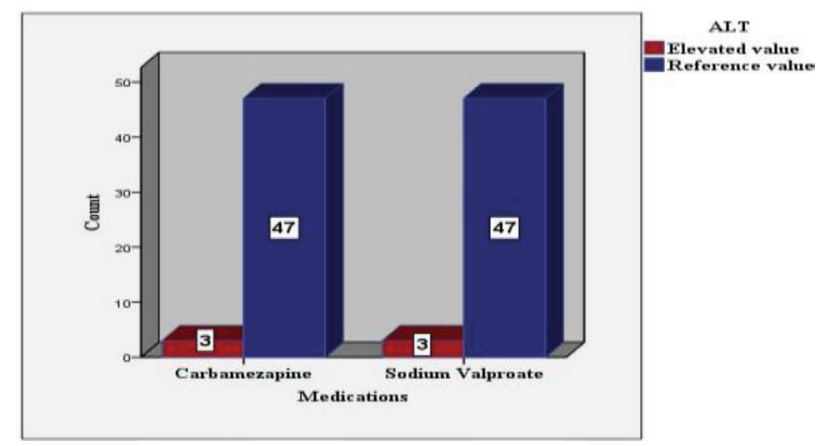

Figure 3 ALT level after 12 months of antiepileptic treatment according to the frequency of the cases.
Logistic regression was used to adjust for different confounders. No significant demographic differences were seen in our data (Table 8).

\subsection{Clinical Findings in the Study Population}

No clinical signs and symptoms of hepatic dysfunction have been detected in the study population, including vomiting, nausea, jaundice, edema, right hypochondrial pain, or hepatomegaly.

\section{DISCUSSION}

Alternation of liver enzymes is a well-known phenomenon with antiepileptic medications [17]. Evaluation of abnormal liver enzyme levels in asymptomatic children can pose a challenge to even an experienced clinician. Thus, this study was conducted to evaluate the liver enzymes of 100 epileptic patients, each of whom received either carbamazepine or sodium valproate for 12 months. The demographic variables and pretreatment liver enzymes were not statically significant and did not affect the course of the treatment.

After 12 months of treatment, the liver enzymes were elevated in $22 \%(22 / 100)$ of the total study population $(p<0.05)$. Despite the

Table 7 Characteristics of the study population based on ALT level ${ }^{a}$

\begin{tabular}{|c|c|c|c|c|}
\hline \multirow{2}{*}{$\begin{array}{l}\text { ALT } \\
\text { Variable }\end{array}$} & \multicolumn{2}{|c|}{ Carbamazepine } & \multicolumn{2}{|c|}{ Sodium valproate } \\
\hline & Normal & Altered & Normal & Altered \\
\hline Age & $7 \pm 3.15$ & $5.6 \pm 3.7^{*}$ & $7.74 \pm 4.20$ & $11.0 \pm 6.92^{*}$ \\
\hline Male & 25 & $1^{*}$ & 28 & $3^{*}$ \\
\hline Female & 22 & 2 & 19 & 0 \\
\hline $\begin{array}{l}\text { AST }(10-40 \mathrm{IU} / \mathrm{L}) \\
\text { Mean } \pm \text { SD }\end{array}$ & $14.93 \pm 6.5$ & $39.3 \pm 0.57^{* *}$ & $14.40 \pm 6.43$ & $48.0 \pm 10.58^{* *}$ \\
\hline
\end{tabular}

${ }^{a}$ Level of significance ( $p$-value) was fixed at $<0.05$. $p>0.05$ (nonsignificant). " $p<0.05$ (significant).

Table 8 Demographic predictors of liver enzyme abnormalities ${ }^{\mathrm{a}}$

\begin{tabular}{llllllll}
\hline & \multicolumn{3}{c}{ AST } & & \multicolumn{3}{c}{ ALT } \\
\cline { 2 - 3 } \cline { 6 - 8 } & \multicolumn{1}{c}{$\boldsymbol{B}$} & SE & $\boldsymbol{p}$ & & $\boldsymbol{B}$ & SE & $\boldsymbol{p}$ \\
\hline Carbamazepine & & & & & & \\
$\quad$ Sex & 2.54 & 3.44 & 0.46 & & 0.53 & 3.43 & 0.89 \\
$\quad$ Age & 0.247 & 0.386 & 0.52 & & 1.35 & 0.35 & 0.11 \\
Sodium valproate & & & & & & \\
$\quad$ Sex & 2.20 & 3.04 & 0.47 & & 0.11 & 2.64 & 0.96 \\
$\quad$ Age & 0.24 & 0.33 & 0.21 & & 0.25 & 0.39 & 0.51 \\
\hline
\end{tabular}

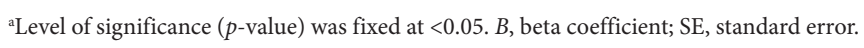

Table 6 Distribution of the study population based on AST level ${ }^{\mathrm{a}}$

\begin{tabular}{lccccc}
\hline \multirow{2}{*}{ AST } & \multicolumn{2}{c}{ Carbamazepine } & & \multicolumn{2}{c}{ Sodium valproate } \\
\cline { 6 - 6 } \cline { 5 - 6 } Variable & Normal & Altered & & Normal & Altered \\
\hline Age & $7.27 \pm 3.19$ & $5.50 \pm 2.75^{*}$ & & $8.16 \pm 4.33$ & $7.25 \pm 4.63^{*}$ \\
Male & 24 & $2^{*}$ & & 22 & $9^{*}$ \\
Female & 16 & 8 & & 16 & 3 \\
AST $(10-40 \mathrm{IU} / \mathrm{L})$ & $23.40 \pm 7.02$ & $45.9 \pm 11.06^{* *}$ & & $24.03 \pm 5.97$ & $45.83 \pm 10.12^{* *}$ \\
$\quad$ Mean \pm SD & & & & & \\
\hline
\end{tabular}

${ }^{a}$ Level of significance ( $p$-value) was fixed at $<0.05$. $p>0.05$ (nonsignificant). $" p<0.05$ (significant). 
statistical significance, the observed alternation of AST and ALT were less than twofold the average value. Similar results were published by Camfield et al. [18] after they examined 199 children on long-term antiepileptic medication prospectively. No severe liver enzymes reactions were reported. In the same way, Hussein et al. [19] concluded that carbamazepine and sodium valproate might associate with mild transient elevation of liver enzymes not linked to hepatocellular injuries.

Among these abnormalities, AST was the most common enzyme elevated in both study groups by $22 \%$, whereas ALT was found abnormal in $6 \%$. Because AST is present in other tissues besides the liver such as the brain and heart, it is considered a less sensitive biomarker for hepatocellular injuries [20]. The low frequency of ALT abnormalities may indicate that AST elevation is not necessarily pathological. This is supported by Jacobsen et al. [21], who found no significant histopathological changes in liver biopsies of six epileptic patients who received long-term anticonvulsant treatment and had a moderate elevation of liver enzymes.

Regarding the enzymes level in both groups, there is no statistical difference after 12 months of treatment. In contrast to our results, Hadzagic-Catibusic et al. [17] found that sodium valproate causes asymptomatic elevation of liver enzymes more frequently than carbamazepine.

It is worth mentioning that no clinical symptoms or signs of hepatic dysfunction have been reported for this study, including vomiting, nausea, jaundice, or right hypochondrial pain. The modest elevation of liver enzymes in asymptomatic children is usually insignificant [22]. This is attributable to the hepatic biotransformation of drugs, such as enzyme induction [23]. Cytochromes are membrane proteins responsible for the metabolism of several antiepileptic drugs [24]. These enzymes are induced by several drugs, especially carbamazepine and valproic acid. Long-term use of such medications can accelerate one's metabolism and reduce one's active form [24]. Similarly, antiepileptic drugs are potent enzymes inducers of other liver enzymes, such as AST and ALT [25]. This can explain the moderate elevation of liver enzymes without clinical or pathological signs of liver injuries [25].

Therefore, it may not be necessary to pursue extensive evaluation for all abnormal results, as this would expose many children to unnecessary procedures and expenses [26]. Regular clinical assessment besides patients and family education can play an essential role in detecting early hepatic injuries. This is in accordance with Schmidt and Siemes [27], who do not support regular repeated monitoring of liver enzymes in asymptomatic patients; however, clinical judgment is paramount. In the same way, Wall et al. [28] screened 206 patients, including children, and suggested clinical assessment rather than routine tests in asymptomatic patients as all elevations were moderate.

Nonetheless, several limitations should be noted and considered for further research. Because there are few observations available on the small study group, it is advisable to have long-term controlled studies on a large sample size with other liver enzymes parameters for further evaluation of the antiepileptic effect.

\section{CONCLUSION}

Our results showed that the alternation of liver enzymes was benign and less than twice the average value. There is no significant enzyme difference between the two groups, and there were no clinical abnormalities of hepatic dysfunction. The study recommends obtaining baseline liver enzymes tests prior to commencement of treatment. However, the benefit of routine screening in asymptomatic patients has not proved. Further controlled studies with a large sample size are warranted.

\section{CONFLICTS OF INTEREST}

The authors declare they have no conflicts of interest.

\section{AUTHORS' CONTRIBUTION}

AM, MA, SA and RB contributed in conceptualization and designing the manuscript. RB contributed in data collection. SA reviewed the edited manuscript. MA contributed in formal analysis and writing the original draft. AM supervised the project. However, all the authors review the manuscript and approve the final draft of the manuscript.

\section{ACKNOWLEDGMENTS}

The authors acknowledge Dr Mudathir Hamad, who edited the manuscript, and are grateful to Dr Hussein Al Hajji for revising the scientific component of the article.

\section{REFERENCES}

[1] Pierce JMS. A disease once sacred. A history of the medical understanding of epilepsy. Brain 2002;125;441-2.

[2] Sirven JI, Noe K, Hoerth M, Drazkowski J. Antiepileptic drugs 2012: recent advances and trends. Mayo Clinic Proc $2012 ; 87 ; 879-89$

[3] Goldenberg MM. Overview of drugs used for epilepsy and seizures: etiology, diagnosis, and treatment. P T 2010;35; 392-415.

[4] Fiest KM, Sauro KM, Wiebe S, Patten SB, Kwon CS, Dykeman J, et al. Prevalence and incidence of epilepsy: a systematic review and meta-analysis of international studies. Neurology 2017;88;296-303.

[5] Fisher RS, Acevedo C, Arzimanoglou A, Bogacz A, Helen Cross J, Elger CE, et al. ILAE official report: a practical clinical definition of epilepsy. Epilepsia 2014;55;475-82.

[6] Seinfeld S, Goodkin HP, Shinnar S. Status epilepticus. Cold Spring Harb Perspect Med 2016;6;a022830.

[7] Kalapos MP. Carbamazepine-provoked hepatotoxicity and possible aetiopathological role of glutathione in the events. Retrospective review of old data and call for new investigation. Adverse Drug React Toxicol Rev 2002;21;123-41.

[8] Chateauvieux S, Morceau F, Dicato M, Diederich M. Molecular and therapeutic potential and toxicity of valproic acid. J Biomed Biotechnol 2010;2010;479364.

[9] Egunsola O, Choonara I, Sammons HM, Whitehouse WP. Safety of antiepileptic drugs in children and young people: a prospective cohort study. Seizure 2018;56;20-5.

[10] Dreifuss FE, Langer DH. Hepatic considerations in the use of antiepileptic drugs. Epilepsia 1987;28;S23-S9. 
[11] Sridharan K, Al Daylami A, Ajjawi R, Al Ajooz HAM. Druginduced liver injury in critically ill children taking antiepileptic drugs: a retrospective study. Curr Ther Res Clin Exp 2020;92;100580.

[12] Camfield P, Camfield C, Dooley J, Farrell K, Langevin P, Humphreys P. Routine screening of blood and urine for severe anticonvulsant reactions in asymptomatic patients is of doubtful value. CMAJ 1989;16;361-3.

[13] Ahmed SN, Siddiqi ZA. Antiepileptic drugs and liver disease. Seizure 2006;15;156-64.

[14] Epilepsies: diagnosis and management: Guidance. NICE. Available from: https://www.nice.org.uk/guidance/cg137/chapter/1-Guidance.

[15] Haslam RHA. Nonfebrile seizures. Pediatr Rev 1997;18;39-49.

[16] Karen Baxter et al. BNF for Children. London: BMJ Group and Pharmaceutical Press, RCPCH Publications Ltd.; 2018.

[17] Hadzagic-Catibusic F, Hasanbegovic E, Melunovic M, Zubcevic S, Uzicanin S. Effects of carbamazepine and valproate on serum aspartate aminotransferase, alanine aminotransferase and gammaglutamyltransferase in children. Med Arch 2017;71;239-42.

[18] Camfield C, Camfield P, Smith E, Tibbies JAR. Asymptomatic children with epilepsy: little benefit from screening for anticonvulsantinduced liver, blood or renal damage. Neurology 1986;36;838-41.

[19] Hussein RRS, Soliman RH, Abdelhaleem Ali AM, Tawfeik MH, Abdelrahim MEA. Effect of antiepileptic drugs on liver enzymes. Beni-Suef Univ J Basic Appl Sci 2013;2;14-19.
[20] Kang KS. Abnormality on liver function test. Pediatr Gastroenterol Hepatol Nutr 2013;16;225-32.

[21] Jacobsen NO, Mosekilde L, Myhre-Jensen O, Pedersen E, Wildenhoff KE. Liver biopsies in epileptics during anticonvulsant therapy. Acta Med Scand 1976;199;345-8.

[22] Vidaurre J, Gedela S, Yarosz S. Antiepileptic drugs and liver disease. Pediatr Neurol 2017;77;23-36.

[23] Brodie MJ, Mintzer S, Pack AM, Gidal BE, Vecht CJ, Scmidt D. Enzyme induction with antiepileptic drugs: cause for concern? Epilepsia 2013;54;11-27.

[24] Punyawudho B, Cloyd JC, Leppik IE, Eugene Ramsay R, Marino SE, Pennell PB, et al. Characterization of the time course of carbamazepine deinduction by an enzyme turnover model. Clin Pharmacokinet 2009;48;313-20.

[25] Ennulat D, Walker D, Clemo F, Magid-Slav M, Ledieu D, Graham M, et al. Effects of Hepatic drug-metabolizing enzyme induction on clinical pathology parameters in animals and man. Toxicol Pathol 2010;38;810-28.

[26] Hoshino M, Heise CO, Puglia P, Almeida ABB, Cukiert A. Hepatic enzymes' level during chronic use of anticonvulsant drugs. Arq Neuropsiquiatr 1995;53;719-23.

[27] Schmidt D, Siemes H. Role of liver function tests in monitoring anticonvulsant use. Mol Diagn Ther 1998;10;321-8.

[28] Wall M, Baird-Lambert J, Buchanan N, Farrell G. Liver function tests in persons receiving anticonvulsant medications. Seizure 1992;1;187-90. 